\title{
DOKTRIN CAVEAT EMPTOR: PENILAIAN TERHADAP AKTA KONTRAK 1950 DAN PERUNDANGAN ISLAM
}

\section{(Caveat Emptor Doctrine: An Evaluation of Contract Act 1950 and Islamic Law)}

Norhoneydayatie Abdul Manap

norhoney@ukm.edu.my

Mat Noor Mat Zain*

mnmz@ukm.edu.my

Pusat Kajian Syariah, Fakulti Pengajian Islam, Universiti Kebangsaan Malaysia.

Pengarang Koresponden (Corresponding Author): *

Rujukan artikel ini (To cite this article): Norhoneydayatie Abdul Manap \& Mat Noor Mat Zain. (2021). Doktrin caveat emptor: Penilaian terhadap Akta Kontrak 1950 dan perundangan Islam. Kanun: Jurnal Undang-undang Malaysia, 33(2), 287-304. http:// doi.org. 10.37052/kanun.33(2)no5

$\begin{array}{llllll}\text { Peroleh: } & \text { 1/12/2020 } & \begin{array}{l}\text { Semakan: } \\ \text { Received: }\end{array} & \text { 17/4/2021 } & \begin{array}{l}\text { Terima: } \\ \text { Accepted: 20/5/2021 }\end{array} & \begin{array}{l}\text { Terbit dalam talian: 6/7/2021 } \\ \text { Published online }\end{array}\end{array}$

\begin{abstract}
Abstrak
Amalan caveat emptor yang menyerahkan sepenuhnya tanggungjawab kepada pembeli agar berhati-hati ketika melakukan transaksi merupakan satu doktrin yang telah diperkenalkan oleh common law sejak abad ke-13 lagi. Menerusi amalan ini, pihak penjual tidak bertanggungjawab untuk mendedahkan segala maklumat yang diketahuinya kepada pembeli. Di Malaysia, doktrin ini tidak jelas dalam mana-mana peruntukan undang-undang. Oleh itu, kajian ini bertujuan untuk menganalisis pemakaian doktrin caveat emptor ini dalam Akta Kontrak 1950. Selain itu, kajian ini juga melihat pandangan perundangan Islam berkaitan dengan
\end{abstract}


amalan doktrin ini. Reka bentuk kajian bersifat kualitatif dengan menggunakan pendekatan analisis dokumen. Data dianalisis secara analisis kandungan. Hasil kajian mendapati terdapat beberapa peruntukan dalam Akta Kontrak 1950 yang mengamalkan doktrin caveat emptor, walaupun tidak diperuntukkan secara jelas dalam akta tersebut. Berdasarkan perundangan Islam pula, doktrin ini tidak sesuai dilaksanakan kerana bertentangan dengan prinsip yang terdapat dalam perundangan Islam. Oleh yang demikian, kajian mencadangkan agar pindaan dibuat terhadap peruntukan berkaitan dengan amalan caveat emptor yang terdapat dalam Akta Kontrak 1950 .

Kata kunci: Caveat emptor; kontrak; transaksi; Akta Kontrak 1950, syarat.

\begin{abstract}
The caveat emptor practice, which is a doctrine introduced by common law since the 13th century, imposes the responsibility on purchasers to be fastidious during a transaction process. In this practice, sellers are not bound to reveal complete information they know to purchasers. In Malaysia, this doctrine is unclear in any legal provision. Therefore, this study aims to analyse the use of the doctrine of caveat emptor in the Contract Act 1950. Furthermore, this study also examines the perspective of Islamic law on the practice of this doctrine. This qualitative study uses document analysis approach to analyse the data collected. The findings revealed several provisions in the Contract Act 1950 that practice the doctrine of caveat emptor, despite the ambiguity of the provision in the Act. Meanwhile, according to Islamic law, the practice of the doctrine is deemed unsuitable as it is against the principles of Islamic law. Hence, this study recommends an amendment of the provision related to the caveat emptor practice in the Contract Act 1950.
\end{abstract}

Keywords: Caveat emptor, contract, transaction, Contract Act 1950, terms and conditions 


\section{PENDAHULUAN}

Amalan caveat emptor telah lama diperkenalkan oleh common law, iaitu sejak abad ke-13 lagi. Amalan ini dilihat masih dilaksanakan oleh para peniaga sama ada dalam urusan transaksi secara bersemuka atau transaksi dalam talian. Di Malaysia, tiada peruntukan undang-undang yang jelas berkaitan dengan caveat emptor kerana tidak ditemui perkataan caveat emptor dalam mana-mana peruntukan undang-undang khususnya dalam Akta Kontrak 1950. Walau bagaimanapun, ciri-ciri amalan caveat emptor ini dapat dilihat terpakai dalam Akta Kontrak 1950. Oleh itu, artikel ini ditulis untuk mengenal pasti dan menganalisis peruntukan Akta Kontrak 1950 berkaitan dengan amalan caveat emptor dalam Akta tersebut. Metodologi yang digunakan ialah analisis dokumen, iaitu menganalisis peruntukan Akta Kontrak 1950, menganalisis pandangan pakar perundangan, serta menganalisis laporan kes berkaitan dengan amalan caveat emptor di Malaysia. Artikel ini juga melihat pandangan perundangan Islam berkaitan dengan amalan caveat emptor dan keperluan untuk penambahbaikan terhadap Akta Kontrak 1950.

\section{PERMASALAHAN CAVEAT EMPTOR}

Dalam pemastian keesahan suatu kontrak, prinsip undang-undang kontrak menetapkan bahawa terma kontrak hendaklah dipersetujui sepenuhnya oleh kedua-dua belah pihak. Persetujuan yang dicapai kemudiannya akan membentuk penerimaan yang menjadi asas penting kepada pembentukan kontrak. Oleh itu, amatlah mustahak terma tersebut dipersembahkan kepada pengguna sebelum keputusan dibuat oleh pengguna sama ada menerima kontrak atau menolaknya. Undang-undang turut menekankan kepentingan memastikan terma kontrak itu jelas, tidak kabur dan dimaklumkan kepada pengguna sebelum penerimaan dibuat. (Parker v South Eastern Railway Co (1877) 2 CPD 416; Thornton v Shoe Lane Parking Ltd [1971] 2 QB 163.)

Sebaliknya, caveat emptor menghendaki pembeli berhati-hati ketika membuat pembelian dengan membuat pemeriksaan terhadap barang yang ingin dibeli. Namun begitu, pada masa ini, pengguna yang kekurangan maklumat akan menyukarkannya untuk berhati-hati ketika membuat pembelian (Azimon \& Zeti Azura 2009). Oleh itu, prinsip caveat emptor perlu dinilai semula agar sejajar dengan kedudukan semasa dan pada masa yang sama tidak bertentangan dengan prinsip hukum syarak. 


\section{CAVEAT EMPTOR COMMON LAW}

Caveat emptor yang berasal daripada common law, memberi maksud "let the buyer beware" merupakan doktrin yang lahir daripada ideologi individualisme pasaran. Doktrin ini tidak meletakkan tanggungjawab atas pihak-pihak berkontrak untuk membuat pendedahan, kerana menurut ideologi individualisme pasaran, pihak berkontrak dibenarkan untuk mendapatkan keuntungan daripada ilmu yang mereka ketahui. Tiada kewajipan umum untuk membuat pendedahan, dan dengan itu pihak berkontrak boleh mengambil peluang atas kejahilan pihak berkontrak yang lain (Adams \& Brownsword 2004). Dalam konteks jualan barang, doktrin caveat emptor tidak memerlukan penjual untuk mendedahkan kerosakan yang berlaku pada barang kontrak jika keadaan kerosakan pada barang tersebut terbuka untuk pemerhatian dan boleh ditemui daripada pemeriksaan secara munasabah, atau pembeli mempunyai peluang untuk memeriksa premis tersebut, dan tidak ada penipuan pada pihak penjual berkenaan dengan keadaan premis tersebut. Doktrin ini terpakai sekiranya pihak penjual tidak membuat penipuan, salah nyata, atau sebarang penyembunyian kerosakan terhadap barang yang dikontrakkan (Johnson, 2008). Oleh itu, tanggungjawab adalah atas pembeli untuk meneliti barangan tersebut sebelum membuat pembelian. Dalam kes $W$ Scott Fell $\&$ Co Ltd v Lloyd (1906) 4 CLR 572 yang dipetik daripada Smith $v$ Hughes (1871) LR 6 QB 597, Blackburn J menyatakan:

The general rule, both of law and equity, in respect to concealment, is that mere silence with regard to a material fact, which there is no legal obligation to divulge, will not avoid the contract although it operates as an injury to the party from whom it is concealed.

Prinsip caveat emptor ini masih diamalkan sehingga abad ke-19 (Mizanur, 1994). Doktrin ini sesuai diamalkan pada ketika itu kerana kuasa rundingan antara pihak berkontrak adalah setara. Ketika doktrin ini mula diperkenalkan di England, kebanyakan masyarakat di England merupakan petani dan urus niaga yang berlaku hanya dalam kalangan petani juga (Alex M. Johnson Jr., 2008; Caryn M. Chittenden, 1992). Penjual pada ketika itu tidak mempunyai tanggungjawab untuk menyatakan atau membuat pendedahan tentang keadaan barang (kebiasaannya lekapan pada tanah) yang dijual kerana para pembeli pada ketika itu mempunyai maklumat berkenaan perkara tersebut. 


\section{CAVEAT EMPTOR DALAM AKTA KONTRAK 1950}

Akta Kontrak 1950 (Akta 136) (Semakan 1974) ialah sumber primer kepada undang-undang kontrak dan mengawal semua aktiviti kontrak di Malaysia. Walaupun terdapat beberapa lagi akta lain berkaitan dengan kontrak atau komersial seperti Akta Jualan Barang 1957, Akta Sewa Beli 1967, dan akta-akta lain lagi yang berkaitan dengannya, akta-akta tersebut hanya mengawal kontrak tertentu sahaja dan mempunyai limitasi tertentu dalam setiap akta tersebut. Sebagai contoh, Akta Sewa Beli 1967 hanya mengawal kontrak sewa beli, dan tidak mengawal kontrak lain.

Peruntukan yang terdapat dalam Akta Kontrak 1950 dipetik dan diguna semula daripada pelbagai sumber lain termasuk Indian Contract Act 1872 tanpa dibuat penelitian dan dianalisis oleh penggubal undangundang berdasarkan kesesuaiannya dengan keadaan di Malaysia,

Menurut sejarah, Indian Contract Act 1872 telah diperluas ke Negeri-Negeri Melayu Bersekutu sebagai Contract Enactment 1899 melalui beberapa pengubahsuaian. Pada tahun 1950, Contract Ordinance secara tidak rasmi diluluskan oleh Federal Legislative Council NegeriNegeri Melayu Bersekutu. Contracts (Malay States) Ordinance 1950 ini diaplikasikan di sembilan buah negeri di Malaysia tidak termasuk Melaka, Pulau Pinang, Sarawak dan Sabah yang masih mengaplikasikan undang-undang Inggeris yang terpakai di England (Visu Sinnadurai 1987). Contract Ordinance 1950 disemak pada tahun 1974, dan secara rasmi dikenali sebagai akta melalui Revision of Laws Act 1968 tanpa melalui Parlimen. Bermula daripada itu, Akta ini diaplikasikan ke seluruh Malaysia pada tahun 1974 dan dirujuk oleh mahkamah sehingga kini (Visu Sinnadurai, 1987).

Akta Kontrak 1950 tidak memperuntukkan secara jelas berkaitan dengan caveat emptor, malah tiada perkataan caveat emptor diperuntukkan dalam Akta tersebut. Namun begitu, merujuk beberapa peruntukan dalam Akta tersebut, doktrin caveat emptor dilihat terpakai dalam beberapa peruntukan, iaitu peruntukan Huraian (Explanation) di bawah seksyen 17 dan juga peruntukan Misalan (Illustration) di bawah seksyen 17. Peruntukan Huraian di bawah seksyen 17 memperuntukkan: "Sematamata membisu mengenai fakta-fakta yang boleh jadi melibatkan kesediaan seorang untuk membuat kontrak bukanlah frod ...". 
Peruntukan Misalan (a) di bawah seksyen 17 pula memperuntukkan:

A menjual kepada B, secara lelong, seekor kuda yang A mengetahui bahawa kuda itu tidak sihat. A tidak memberitahu apa-apa kepada B bahawa kuda itu tidak sihat. Ini bukanlah frod oleh A.

Peruntukan di bawah Misalan (d) pula memperuntukkan:

A dan $\mathrm{B}$, dua orang pedagang, membuat kontrak. A dapat maklumat sendirian mengenai perubahan harga yang boleh menyentuh kerelaan B untuk meneruskan kontrak itu. A tidak terikat untuk memberitahunya kepada B.

Berdasarkan misalan tersebut, hanya peruntukan Misalan (b) yang mewajibkan untuk membuat pendedahan, iaitu apabila terdapat hubungan antara pihak berkontrak,

B ialah anak perempuan A dan ia baharu saja dewasa. Di sini ada hubungan antara kedua belah pihak yang mewajibkan A untuk memberitahu B jika kuda itu tidak sihat.

Berdasarkan peruntukan tersebut jelas bahawa pihak berkontrak khususnya penjual tidak mempunyai kewajipan untuk mendedahkan maklumat yang diketahuinya kepada pihak lain. Perkara ini selari dengan maksud doktrin caveat emptor, iaitu meletakkan pihak pembeli agar berhati-hati dan membuat pemeriksaan sebaik-baiknya terhadap barang yang ingin dibelinya. Walaupun Akta Kontrak 1950 tidak secara jelas memperuntukkan caveat emptor, namun, peruntukan Huraian dan Misalan tersebut jelas mengaplikasikan doktrin caveat emptor.

Selain itu, mahkamah memutuskan beberapa kes yang juga menunjukkan aplikasi doktrin caveat emptor dalam Akta Kontrak 1950 seperti yang dapat dilihat dalam Lau Hee Teah v Hargill Engineering Sdn Bhd \& Anor [1980] 1 MLJ 145, Abdoolcader J menyatakan:

This amount to misrepresentation as there was no active duty on the part of the seller to inform the hirer of these matters.

The Explanation to s.17 of the Contracts Act 1950 clearly states that mere silence as to facts likely to affect the willingness of a person 
to enter into a contract is not fraud, unless the circumstances of the case are such that, regard being had to them, it is the duty of the person keeping silence to speak, or unless his silence is, in itself, equivalent to speech ...

Begitu juga dalam kes Karuppannan Chellappan $v$ Chong Lee Chin [2000] 7 CLJ 265, berlaku kontrak jual beli yang terdapat kenyataan di dalam kontrak itu bahawa bangunan yang dijual adalah "free from all encumbrances", sedangkan jika pihak plaintif ingin membeli bangunan tersebut, dia perlu mengalihkan tingkap yang tersembul keluar dengan menggunakan perbelanjaannya sendiri. Mahkamah memutuskan bahawa prinsip caveat emptor terpakai kepada plaintif kerana plaintif merupakan peniaga restoran tempatan yang mempunyai perniagaan hampir dengan bangunan tersebut. Plaintif juga telah membuat tinjauan terhadap bangunan tersebut sebelum membuat pembelian, dan sepatutnya telah melihat tingkap tersebut yang tersembul keluar. Abdul Hamid Embong $\mathrm{J}$ menyatakan:

Plaintiff failed to make inquiries about them or hire a surveyor to determine the boundary of the building and whether the protrusions had trespassed into the adjacent lot. A prudent purchaser of real property will take the precaution to make a survey and if he omitted to take this precaution he did on his own risk.

The preposition in law is that there is no fiduciary relationship between a vendor and purchaser.. Thus, an uncommunicative or taciturn vendor cannot be faulted if he failed to disclose any patent defeat such as the window protrusions found in the instant case.

Selain itu, peruntukan "Kecualian" (Exception) yang terdapat di bawah seksyen 19 juga memperlihatkan pemakaian prinsip caveat emptor apabila memperuntukkan:

Jika kerelaan itu disebabkan oleh salah nyata atau oleh pembisuan yang menjadi frod dalam pengertian seksyen 17, maka kontrak itu, meskipun begitu, tidak boleh dibatalkan jika pihak yang kerelaannya disebabkan sedemikian ada jalan untuk mengetahui kebenarannya dengan menggunakan ketekunan yang lazim. 
Peruntukan Kecualian di bawah seksyen 19 ini menyatakan sekiranya pihak berkontrak bersetuju untuk memasuki kontrak disebabkan oleh salah nyata, akan tetapi mempunyai jalan untuk mengetahui kebenaran dengan ketekunan yang lazim (ordinary diligence), maka kontrak tersebut bukan boleh batal. Oleh itu, pemberian remedi pembatalan kontrak di Malaysia hanya dibenarkan apabila pihak yang terdorong tidak mempunyai ikhtiar atau jalan untuk mencari kebenaran melalui kerajinan yang biasa. Dalam kes Tan Chye Chew \& Yg Lain-Lain v Eastern Mining Metals Co. Ltd [1965] 1 MLJ 201, mahkamah menyatakan terdapat salah nyata berlaku, tetapi kontrak tidak dapat dibatalkan kerana pihak responden mempunyai ikhtiar untuk mencari kebenaran melalui kerajinan yang biasa. Jika pihak yang terdorong dapat mencari kebenaran melalui kerajinan luar biasa, pasti pihak yang membuat salah nyata tidak boleh melepaskan diri daripada tanggungan (Shaik Mohd. Noor Alam S.M. Hussain, 2013).

Beberapa kes tentang mengetahui kebenaran dengan ketekunan yang biasa (ordinary diligence) diputuskan oleh mahkamah. Antaranya termasuklah kes Beca (Malaysia) Sdn Bhd v Tan Choong Kuang \& Anor [1986] 1 MLJ 390, SC Lee Hun Hoe CJ (Borneo) juga merujuk kepada Kecualian seksyen 19 AK 1950,

The buyers could not be expected to know that the developers had no license at that time. It would be expecting too much of the buyers to say that they 'had means of discovering the truth with ordinary diligence' to quote the words of section 19 of the Contract Act 1950.

Selain itu, dalam kes Tay Tho Bok \& Anor v Segar Oil Palm Estate Sdn Bhd [1996] 3 MLJ 181 Mohd Ghazali J menyatakan:

I am of the view that the Exception to section 19 of the Contract Act 1950 as laid down above is not applicable to the instant case as the evidence has shown that the plaintiffs did not have the means of discovering the truth with ordinary diligence, as even the land office Kota Tinggi did not have specific records of the dealing relating to the acquisition for the pipeline reserve and dealing relating to the laying of the transmission lines... Furthermore, the search at the land office ... did not as reveal the existence of any encumbrances on the said land. 
Dalam kes Low Keang Guan v Sin Heap Lee-Marubeni Sdn Bhd [2005] 7 MLJ 216 pula Abdul Malik Ishak J menyatakan, "In my judgement, the contract between the parties was not voidable because the plaintiff had the means of discovering the truth with ordinary diligence and the Exception to section 19 of the Contracts Act 1950 does not apply." Dalam kes Sealdeck (Kuala Lumpur) Sdn Bhd v Onn Choon Koi@ Ng Ching Kwai [2008] 4 MLJ 438, Mohd Hishamudin J menyatakan,

I hold that this allegation of misrepresentation is baseless. The plaintiff had the means of knowing about the condition imposed on the title of the land by means of a simple land search at the land office. In this regard, I refer to the Exception to section 19 of the Contracts Act 1950.

Berdasarkan beberapa peruntukan Akta Kontrak 1950 dan juga kes yang telah diputuskan oleh mahkamah, jelas bahawa doktrin caveat emptor terpakai dalam Akta Kontrak 1950 walaupun tidak secara jelas terdapat perkataan caveat emptor dalam Akta Kontrak 1950.

\section{CAVEAT EMPTOR MENURUT PERUNDANGAN ISLAM}

Islam mewajibkan umatnya amanah dan jujur dalam sebarang transaksi. Berkata benar adalah salah satu menifestasi amanah dan jujur. Firman Allah SWT dalam Surah al-Baqarah ayat 42 bermaksud (al-Quran 2:42): "Dan janganlah kamu campur adukkan yang benar itu dengan yang salah, dan kamu sembunyikan yang benar itu pula padahal kamu semua mengetahuinya." Allah SWT juga berfirman dalam Surah al-Imran ayat 167 yang bermaksud (al-Quran 3:167): "Mereka selalu menyebut dengan mulutnya apa yang tidak ada dalam hatinya."

Berkata benar danjujur juga bukan sahaja boleh menyebabkan transaksi yang dilakukan mendapat keberkatan tetapi juga boleh menentukan sama ada kontrak itu menjadi mengikat (lazim) atau tidak. Sabda Rasul SAW, yang bermaksud:

"Penjual dan pembeli memiliki hak khiyar (tetap melanjutkan jual beli atau membatalkannya) selama keduanya belum berpisah. Jika keduanya berkata benar dan menjelaskan apa adanya, maka jual beli mereka diberkahi, tetapi jika keduanya menyembunyikan kecacatan 
yang ada dan berkata dusta, maka jual beli mereka tidak diberkati."

(Bukhari 2002, Kitab al-Buyuc, Bab al-Baycan bi al-Khiyar

Amalan mendedahkan butiran tentang perkara yang dikontrakkan amat dititikberatkan dalam perundangan Islam sama ada perkara tersebut baik atau sebaliknya. Kewajipan mendedahkan kecacatan atau kerosakan yang terdapat pada barang yang dikontrakkan adalah perlu kerana semua transaksi mesti dilakukan berasaskan persetujuan bersama atas dasar saling rela-merelai antara pihak berkontrak seperti firman Allah SWT dalam Surah an-Nisa' ayat 29 yang bermaksud :

\footnotetext{
"Wahai orang-orang yang beriman, janganlah kamu makan (gunakan) harta-harta kamu sesama kamu dengan jalan yang salah (tipu, judi dan sebagainya), kecuali dengan jalan perniagaan yang dilakukan secara suka sama suka di antara kamu ...”
}

Selain itu, terdapat beberapa dalil khusus mengenai kewajipan membuat pendedahan dalam melaksanakan kontrak, iaitu hadis yang menyuruh menyatakan aib barang dan melarang menyembunyikannya. Dalam sebuah hadis yang disahihkan oleh al-Hakim, Uqbah bin Amir r.a. mendengar Nabi SAW bersabda yang maksudnya (Ibn Majah, t. t., Kitab al-Tijarat, Bab Man ba'a 'Ayban Falyubayynah ): "Seorang Muslim adalah saudara bagi Muslim yang lain, maka tidak halal dia menjual kepada saudaranya sesuatu barang yang ada kecacatan kecuali jika dia jelaskan."

Aishah juga meriwayatkan bahawa seorang laki-laki membeli seorang hamba, lalu digunakan untuk bekerja. Kemudian beliau mendapati terdapat kecacatan pada hamba tersebut, lalu mengembalikan kepada penjual. Lantas penjual mengadu kepada Nabi SAW bahawa pembeli telah mempekerjakan (mengambil manfaat) terhadap hambaku. Rasulullah bersabda: "Hak mendapatkan hasil itu disebabkan oleh keharusan menanggung kerugian" (Ibn Majah t.t, Kitab al-Tijarat, Bab al-Kharaj bi al-Daman).

Dalam hadis lain yang diriwayatkan oleh Abu Hurairah r.a. bahawa Nabi SAW berjalan berdekatan dengan selonggok makanan lalu baginda memasukkan tangannya ke dalam longgokan itu. Tiba-tiba jari baginda terkena sesuatu yang basah. Baginda bertanya: "Apa semuanya ini wahai tuan punya makanan? Orang itu menjawab: Terkena hujan, wahai Rasulullah. Baginda bersabda: Mengapa tidak kamu letakkan di atas 
supaya orang ramai dapat melihatnya. Sesiapa yang menipu maka dia bukan daripada kalanganku." (Muslim 1929, Kitab al-Iman, Bab Qawl alNabi SAW Man Ghashana).

Hadis-hadis tersebut jelas menunjukkan bahawa tidak boleh menyembunyikan sesuatu perkara atau fakta yang menjadi asas kepada sesuatu transaksi. Jika dilakukan maka boleh menjadikan kontrak itu tidak mengikat dan boleh dibatalkan oleh pihak yang terpedaya.

Terdapat juga kaedah fiqh "tidak boleh dinisbahkan kata-kata kepada orang yang tidak mengatakannya, tetapi diamnya dalam situasi memerlukan penerangan dan dikira penerangannya" (al-Burnu, 1996). Dengan ini, jika seseorang itu diam dalam perkara yang dia tidak boleh diam maka tindakannya diambil kira. Begitu juga jika penjual diam daripada menyatakan kebenaran sedangkan ia tidak boleh diam maka dia boleh diambil tindakan kerana seolah-olah mengakui untuk tidak memberitahu kedudukan yang sebenar. Oleh yang demikian, dalam konteks caveat emptor ini, apabila pihak berkontrak tidak membuat pendedahan, dan berdiam diri pihak tersebut boleh dianggap sebagai penerangan daripadanya. Keadaan ini akan menyebabkan pihak satu lagi akan membuat anggapan yang salah terhadap perkara yang dikontrakkan itu dan menyebabkan berlakunya ketidakadilan dalam berkontrak.

Berdasarkan dalil tersebut, jelas bahawa perundangan Islam tidak membenarkan prinsip caveat emptor ini terpakai. Pihak berkontrak wajib mendedahkan kecacatan yang terdapat pada barang kontrak agar kontrak dapat dilakukan dengan telus. Sekiranya seseorang menyembunyikan aib daripada diketahui orang yang berakad, perbuatan tersebut dianggap atau dinamakan sebagai tadlis dan boleh dilakukan khiyar tadlis, iaitu pilihan sama ada membatalkan kontrak atau melaksanakan kontrak yang dimasukinya (Badrān, 1973). Menurut Shaik Noor Alam (1998) aspek yang paling asas dalam pendekatan Islam terhadap perlunya iktikad yang baik dan urusan yang adil ialah larangan terhadap kejahilan atau jahil kerana boleh menyebabkan riba atau gharar yang mengakibatkan kontrak terbatal. Maklumat yang cukup diperlukan sebelum memasuki kontrak. Oleh yang demikian, amalan caveat emptor dilihat tidak bersesuaian dengan prinsip ini.

\section{PERBINCANGAN}

Amalan caveat emptor yang telah dicetuskan oleh common law masih terpakai sehingga hari ini dalam kontrak-kontrak yang dimasuki oleh 
orang ramai. Amalan ini meletakkan tanggungjawab kepada pihak pembeli untuk berhati-hati dalam proses pembelian bagi memastikan pembeli tidak mengalami kerugian. Melalui prinsip ini juga bermaksud pihak penjual tidak bertanggungjawab untuk mendedahkan maklumat kepada pembeli.

Amalan ini dilihat sesuai untuk diamalkan pada abad ke-13 kerana pada ketika itu kuasa tawar-menawar masih lagi seimbang. Kebanyakan masyarakat yang berkontrak pada ketika itu hanyalah para petani yang menjual hasil kebun mereka. Oleh itu, masyarakat pada ketika itu mempunyai maklumat yang jelas berkaitan dengan perkara yang mereka kontrakkan.

Namun begitu, selepas revolusi perindustrian, keadaan masyarakat berubah. Pada ketika ini terdapat beberapa golongan pihak berkontrak, iaitu antara peniaga dengan peniaga (B2B) serta peniaga dengan pengguna (B2C). Pada ketika ini juga kuasa tawar-menawar sudah tidak seimbang. Terdapat golongan yang mempunyai kedudukan yang lebih tinggi dan mempunyai banyak maklumat berkaitan dengan perkara yang mereka kontrakkan. Selain itu terdapat juga golongan yang lemah yang tidak mempunyai maklumat yang lengkap berkaitan dengan perkara yang dikontrakkan (Lee Mei Pheng \& Ivan Jeron Detta, 2013). Oleh itu, jika amalan caveat emptor ini diteruskan, maka akan berlaku penindasan terhadap golongan yang lemah ini.

Dalam konteks negara Malaysia, amalan caveat emptor ini tidak diperuntukkan secara jelas dalam mana-mana peruntukan perundangan. Begitu juga tiada peruntukan yang jelas berkaitan dengan caveat emptor dalam Akta Kontrak 1950. Namun begitu, berdasarkan kes yang telah diputuskan oleh mahkamah, dan juga melalui pandangan pakar perundangan, jelas bahawa amalan caveat emptor terpakai dalam Akta Kontrak 1950 khususnya di bawah peruntukan seksyen 17 dan di bawah peruntukan seksyen 19.

Berdasarkan prinsip caveat emptor, pembeli bertanggungjawab membuat pemeriksaan terhadap barang yang ingin dibelinya. Namun begitu, dari aspek kepenggunaan, prinsip ini secara tidak langsung dianggap tidak lagi signifikan akibat perkembangan semasa dan teknologi moden. Sebaliknya pengusaha atau penjual perlu diletakkan tanggungjawab untuk "berjaga-jaga" bagi memastikan produk jualan mereka mampu memberikan kepuasan kepada pembeli atau pengguna. Oleh itu, pelaksanaan doktrin caveat venditor, iaitu "peniaga haruslah 
berhati-hati" lebih sesuai diaplikasikan. Undang-undang perlu mengenakan tanggungjawab dan liabiliti terhadap pengusaha atau peniaga yang memperihalkan cap dagangan dan penyataan palsu termasuk aspek pengendalian dan amalan palsu atau mengelirukan berhubungan dengan pembekalan barang-barang dan perkhidmatan (Alias, Harlida, Nurretina, 2013). Peniaga juga haruslah mempunyai tanggungjawab bagi memastikan sesuatu produk atau barangan adalah selamat, halal dan suci (Elistina, 2013).

Menurut perundangan Islam pula, amalan ini pada asasnya tidak dibenarkan seperti dinyatakan dalam al-Quran dan sunah. Hal ini jelas jika perkara yang tidak dinyatakan tersebut boleh menyebabkan pihak satu lagi tidak akan melakukan transaksi dengannya jika mengetahui kedudukan sebenar. Penyembunyian kebenaran mencacatkan kerelaan, dan tindakan sedemikian dikira sebagai penipuan. Pihak yang tertipu boleh memilih sama ada meneruskan akad atau membatalkannya.

Kedudukan tersebut sejajar dengan syarat barangan dalam semua jenis kontrak yang mensyaratkannya hendaklah dimaklumi oleh keduadua pihak terlibat, agar tidak ada kejahilan yang boleh mencetuskan perselisihan itu. Semua mazhab fiqh bersepakat (al-Kasani, 1982; al-Dardir, t.t.; al-Sharbini, 1958; al-Buhuti, t.t.) bahawa syarat ini


Hal ini berdasarkan hadis-hadis yang melarang jual beli gharar dan jual beli sesuatu yang tidak wujud, serta berdasarkan konsep kerelaan dalam kontrak (al-Zuhayli, 1989). Pensyaratannya pada kontrak selainnya berlaku perselisihan pendapat antara ulama. Mazhab Shafii dan Hanbali (al-Ghazali, 1997; Badran, 1973) mensyaratkannya pada semua jenis kontrak, sama ada kontrak tabaruk atau kontrak mua'wadah, berkaitan dengan harta dan yang tidak berbentuk harta seperti kontrak perkahwinan. Mazhab Hanafi juga mengatakan sedemikian, tetapi mereka hanya tidak mensyaratkannya pada sesetengah kontrak tabaruk seperti wasiat dan kafalah kerana kejahilan dalam kedua-duanya tidak membawa pertelingkahan. Sementara mazhab Maliki (Ibn Juzay, t.t.)

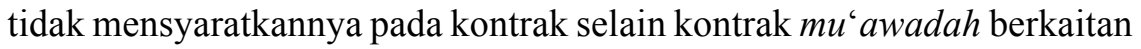
dengan harta.

Namun demikian, dalam memberikan maklumat kepada pihak kedua, penjual tidak perlu menyatakan semuanya tetapi sesuai dengan keadaan subjek akad. Sekiranya subjek atau barang itu wujud dalam majlis kontrak, kewujudannya dimaklumi dengan menunjukkan ke 
arahnya, sekali pun barang itu tersorok seperti gandum di dalam karung atau seumpamanya. Perkara ini mengikut persepsi mazhab Hanafi dan Hanbali (Ali Quraah, t.t.). Mengikut mazhab Maliki, sesuatu yang ada dalam majlis mestilah dilihat selagi tidak ada kesulitan berbuat demikian, dan jika sukar untuk dilihat boleh dijalankan dengan menjelaskan sifatsifatnya (al-Hattab, 1992). Mazhab Shafii lebih ketat dengan memestikan barang tersebut dilihat untuk mencapai tahap maklum (al-Ramli, 1984). Subjek kontrak yang tidak ada dalam majlis menjadi tentu dan maklum dengan menjelaskan sifat-sifat yang boleh mencegah daripada berlakunya kejahilan yang ketara (al-Zuhayli, 1989). Sementara itu mazhab Shafii, mengikut qaul jadid mensyaratkan barang itu mesti dilihat walau apa-apa keadaannya sekalipun (al-Sharbini, 1958). Perlu diingatkan bahawa jika penjual maklum tentang kecacatan maka beliau mesti memaklumkannya berdasarkan prinsip asas yang dibincangkan sebelum ini.

Namun demikian, dalam kontrak pertukaran (mu'awadah) seperti jual beli, sebahagian ulama membolehkan pihak penjual boleh mensyaratkan kepada pembeli bahawa beliau tidak bertanggungjawab terhadap sebarang aib pada barangan. Dengan ini, jika pembeli bersetuju dan melakukan akad berasaskan kedudukan tersebut, maka jika terdapat aib beliau tidak boleh mengembalikan barang belian kerana syarat tersebut telah jelas dan beliau rela menggugurkan haknya. Namun demikian, pensyaratan tersebut dibolehkan dengan syarat penjual tidak mengetahui sememangnya terdapat aib pada barang tersebut. Jika beliau tahu dan mensyaratkan sedemikian kepada pembeli maka dikira satu penipuan.

Namun begitu, dari segi kesahihan kontrak yang dilakukan, mengikut al-Nawawi (2001) dalam kitab al-Majmu', jika penjual tanpa menerangkan aib pada perkara yang dikontrakkan maka hukum jual beli itu sah tetapi berdosa.

Dalam al-Mawsu'ah al-Fiqhiyyah al-Kuweitiyyah (1404H-1427H) menyatakan bahawa fuqaha berpendapat, jika penjual mengetahui terdapat sesuatu pada barang jualan yang membolehkan pembeli tidak menyenanginya maka beliau hendaklah memberitahunya secara jelas serta memberikan gambaran menyeluruh di samping pernyataan tersebut jika kecacatan itu tersembunyi kerana kadang-kadang pembeli boleh berlapang dada pada sesuatu barang tetapi tidak pada barang yang lain dengan sifat yang sama. Hukumnya haram jika beliau tidak menyatakannya dan seterusnya beliau berdosa. Namun demikian, jika jual beli tersebut masih berlangsung dalam keadaan penjual menyembunyikan aib tersebut maka 
jual beli tersebut sahih tetapi penjualnya berdosa dan melakukan maksiat mengikut jumhur fuqaha. Pada masa yang sama pembeli jika mengetahui kedudukan sebenar maka beliau berhak untuk membuat pilihan sama ada meneruskan kontrak atau membatalkannya. Oleh sebab itu, ulama mengkategorikan jual beli sedemikian sebagai jual beli yang tidak lazim atau tidak mengikat kerana pembeli boleh membuat pilihan tersebut. Jika pembeli merelakan dengan aib tersebut maka kontrak itu dikira sah tanpa perlu dilakukan kontrak yang baharu.

\section{KESIMPULAN}

Islam pada asasnya mensyaratkan sesuatu yang menjadi perkara asas dalam kontrak hendaklah diketahui oleh setiap pihak mengikut kesesuaian perkara tersebut dan keadaannya. Hal ini kerana konsep syarat dalam Islam membentuk tanggungjawab atas pihak yang membuat syarat itu (Norhoneydayatie et al., 2014). Namun demikian, ulama membolehkan untuk mengadakan syarat bebas daripada aib oleh pihak penjual tetapi hendaklah aib tersebut tidak diketahui oleh penjual sebelumnya. Oleh itu, perkara yang sepatutnya diketahui oleh pihak-pihak berkontrak mesti dinyatakan. Amalan dalam caveat emptor yang membenarkan penjual tidak memberitahu perkara yang boleh menghilangkan kerelaan pihak berkontrak adalah sangat bertentangan dengan perundangan Islam. Dalam Islam, hal ini merupakan satu kesalahan dan pihak yang melakukannya dikira berdosa. Namun demikian, kontrak yang berlaku dalam keadaan pembeli tidak mengetahui kedudukannya itu masih dikira sahih, tetapi pembeli mempunyai pilihan sama ada meneruskan kontrak atau membatalkannya jika beliau mengetahui aib tersebut.

Oleh itu, kajian ini mendapati amalan caveat emptor yang terdapat dalam Akta Kontrak 1950 adalah tidak bertepatan dengan perundangan Islam. Selain bercanggah dengan perundangan Islam, amalan ini juga dilihat tidak memberikan keadilan kepada pihak berkontrak kerana meletakkan tanggungjawab yang berat atas pembeli. Tambahan pula pada era globalisasi ini, maklumat yang diperoleh oleh pembeli amat terbatas dan kuasa rundingan antara pihak berkontrak juga tidak seimbang. Oleh itu, cadangan amalan caveat venditor merupakan satu cadangan yang baik dalam usaha mengisi kelemahan terhadap amalan caveat emptor. Oleh yang demikian, untuk memastikan perundangan kontrak di Malaysia selari dengan perundangan Islam dan mampu menyahut cadangan bagi 
melaksanakan caveat venditor, seterusnya demi menegakkan keadilan antara pihak berkontrak, maka amalan caveat emptor yang terdapat dalam Akta Kontrak 1950 hendaklah dipinda atau dimansuhkan.

\section{PENGHARGAAN}

Penghargaan dan terima kasih kepada Kementerian Pengajian Tinggi Malaysia (KKM) yang memberikan projek Pembinaan Garis Panduan Mengelak Penipuan dalam Pembelian dalam Talian (dalam talian), No Projek: FRGS / 1/2019 / SSI10 / UKM / 03/1.

\section{RUJUKAN}

Adams, J.N. \& Brownsword, R. (2004). Understanding contract law. Ed. ke-4. Sweet \& Maxwell Ltd., London.

Ali Qura'ah. (t. th). Ahkam al-'Uqud fi al-Shari'ah al-Islamiyyah, Dar Misr li al-Tiba`ah.

Alias Azhar, Harlida Abdul Wahab, Nurretina Ahmad Shariff Muhammad Hafiz Badarulzaman. (2013). Produk makanan halal: Perspektif hukum dan undang-undang (Halal food products: perspective of Islamic rulings and the laws). Nurdeng Deuraseh, Russly Abdul Rahman Shuhaimi Mustafa, Jamilah Bakar \& Dzulkifly Mat Hashim (Eds.). Halalan Thoyyiban Perspektif Malaysia. Institut Penyelidikan Produk Halal Universiti Putra Malaysia, Universiti Putra Malaysia.

Alex M. Johnson Jr. (2008). 'An economic analysis of the duty to disclose information: lessons learned from the caveat emptor doctrine' 45. San Diego L. Rev. 79, 102.

al-Bahuti al-Buhuti, Mansur ibn Yunus ibn Idris. (t. th.). Kashshaf al-Qinac can Matn al-Iqnac. 6 jil. Maktabah al-Nasr al-Hadithah.

al-Burnū, Muḥammad Șidqi bin Aḥmad bin Muḥammad. (1996). Al-Wajīz $f i$ cIdah Qawā'id al-Fiqhī al-Kulliyyah. Muassasah al-Risālah.

al-Dardir, Abu al-Barakat Sayidi Ahmad. (t. th.). al-Sharh al-Kabir. Isa alHalabi.

al-Ghazali, Hujat al-Islam Abu Hamid Muhammad ibn Muhammad al-Ghazali. (1979). al-Wajiz fi Fiqh Mazhab al-Imam al-Shafi i. Dar al-Ma`arifah li alTiba ah wa al-Nashr.

al-Hattab, Abu cAbdillah Muhammad ibn Muhammad ibn cAbd al-Rahman al-Maghribi. (1992). Mawahib al-jalil li sharh mukhtasar al-khalil. Cet bersama al-Taj wa al-aklil, Dar al-Rashad al-Hadithah.

al-Kasani, Abu Bakr ibn Mas'ud. (1982). Bada' $i$ ' al-Sana 'i 'fi Tartib al-Shara' $i$. Dar al-Kitab al-'Arabi. 
al-Nawawi, Muhyi al-Din Yahya bin Sharaf. (2001). al-Majmu’ Sharh alMuhazab. Maktabat al-Irshad.

al-Ramli, Muhammad bin Shihab al-Din. (1984). Nihayat al-Muhtaj ila Sharh al-Minhaj. Dar al-Fikr.

al-Sharbini, Mohamad al-Khatib. (1958). Mughni al-Muhtaj Ila Macrifati Macani Alfaz al-Minhaj. Matbacah Mustafa al-Babi al-Halabi Wa Awladuhu, Kaherah.

Azimon Abdul Aziz \& Zeti Azura Mohamed Hussein. (2009). Impak bioteknologi ke atas perlindungan pengguna: Aspek undang-undang berhubung keselamatan produk. Jurnal Pengurusan, 29, 33-56.

Badrān, Abu al-Ain̄̄ Badrān. (1973). Al-Sharīcah al-Islāmiyyah. Maktabah Min kāf.

Caryn M. Chittenden. (1992). From caveat emptor to consumer equity-The implied warranty of quality under the uniform common interest ownership act'. Wake Forest Law Review, 27, 571.

Elistina Abu Bakar. (2013). Undang-undang pengguna dalam konteks halalan toyyiban di Malaysia. Nurdeng Deuraseh, Russly Abdul Rahman Shuhaimi Mustafa, Jamilah Bakar \& Dzulkifly Mat Hashim (Eds.), Halalan thoyyiban perspektif Malaysia. Institut Penyelidikan Produk Halal Universiti Putra Malaysia.

Ibn Juzay. (t. th), al-Qawanin al-Fiqhiyyah. Dar al-Kutub al-cIlmiyyah.

Ibn Majah, Abu cAbdullah Muhammad ibn Yazid al-Qayrawani. (t.th). Sunan Ibn Majah. Dar al-Fikr.

Johnson, A. (2008). An economic analysis of the duty to disclose information: Lessons learned from The Caveat Emptor Doctrine. San Diego Law Review, 45, 79-132.

Lee Mei Pheng \& Ivan Jeron Detta. (2013) Commercial law. Ed. ke-2. Oxford Fajar Sdn Bhd, Shah Alam, Selangor.

Mizanur Rahman. (1994). Consumer protection law and the Swedish approach. Prudential Publications.

Muhammad Noor Haji Ibrahim, Abdullah Basmeh, (2010). Tafsir Pimpinan arRahman kepada Pengertian al-Quran (30 juzuk). Darul Fikir.

Muslim. (1929). Sahih. Cet. bersama Sharh al-Nawawi, al-Matba'ah alMisriyyah, al-Azhar.

Norhoneydayatie, A. M., Laluddin, H., Mohd. Kusrin, Z., Salleh, A. D., Mat Zain, M. N., Muhammad Husni, A., ... Omar, A. F. (2014). Stipulation in contract from Islamic and Malaysian legal perspectives. Asian Social Science, 10(2), 112-117. https://doi.org/10.5539/ass.v10n2p112

Shaik Mohd Noor Alam bin S.M. Hussain. (1998). Kontrak \& kewajipan undangundang di beberapa negara Asean yang dipilih. Dewan Bahasa dan Pustaka. 
Shaik Mohd. Noor Alam bin S.M. Hussain. (2013). Undang-undang komersil di Malaysia. Ed. ke-2, Dewan Bahasa dan Pustaka.

Visu Sinnadurai. (1987). The law of contract in Malaysia and Singapore: Cases and Commentary.Ed. ke-2. Butterworth \& Co (Asia) Pte Ltd.

Wahbah al-Zuhayli. (1989). al-Fiqh al-Islami wa Adillatuh. Dar al-Fikr.

Wizarat al-Awqaf wa al-Shu'un al-Islamiyyah. (1404H-1427H). al-Mawsucah al-Fiqhiyyah al-Kuweitiyyah. Wizarah al-Awqaf al-Kuweitiyyah. 